\title{
Escucho para que me oigan. La conquista del Perú (1748) de Fray Francisco del Castillo y el gremio de los naturales
}

\author{
Martha Barriga Tello \\ Universidad Nacional Mayor de San Marcos \\ martha_barriga@yahoo.com.ar
}

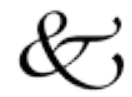

\begin{abstract}
Resumen
Se estudia La conquista del Perú (1748) obra del criollo fray Francisco del Castillo y Tamayo OM, conocido como "El ciego de la Merced". Nuestro objetivo, en primer término, es destacar el sutil valor reivindicativo de la obra que fue encargada por la comunidad indígena al clérigo mercedario en una fecha significativa como fue la coronación del nuevo rey Fernando VI. El análisis, luego, nos permitirá comprobar que obras como $L a$ conquista del Perú fueron el síntoma de un nuevo espíritu, compartido por muchos.
\end{abstract}

Palabras claves: Francisco del Castillo y Tamayo, La conquista del Perú, Literatura de la Colonia, Teatro colonial.

\begin{abstract}
In this article is studied The conquest of Peru (1748) by Fray Francisco del Castillo and Tamayo OM, known as "The blind of La Merced". Our first purpose is explain the subtle protest value of the work that was commissioned by the Indian community to mercedario cleric in a significant date as it was the coronation of the new King Ferdinand VI. The analysis allow us to check that works like The conquest of Peru were a symptom of a new spirit, shared by many.
\end{abstract}

Keywords: Tamayo and Francisco del Castillo, The Conquest of Peru, Literature of the Colony, Colonial Theatre. 
Fray Francisco de Paula del Castillo y Tamayo O.M. (2/04/1716 - diciembre 1770) ${ }^{1}$ es uno de los autores criollos más prolíficos de la época virreinal. Conocido como "El ciego de la Merced", sus obras comprenden el drama, la poesía y la traducción. Fue hijo de la limeña Jordana Tamayo de Salazar y del poeta español Luis del Castillo y Andraca que radicó en el Perú desde 1701 y, después de ser Corregidor de Piura y luego de Saña, se estableció en Lima donde instaló una imprenta en la calle Mercaderes, hasta su muerte en 1733. Esta circunstancia, así como el de tener un preceptor que su padre buscó para él por un serio problema de visión que no le permitió asistir a una instrucción regular, facilitaron que Francisco estuviera próximo a la experiencia literaria que cultivó con éxito desde muy joven. La misma que continuó cuando ingresó a la Orden de La Merced como hermano lego en 1734 y en la que, después de superar varios inconvenientes, emitió sus votos el 7 de enero de 1741 (Lohmann, 1945:416417; Aparicio 2001:458).

En un documento del 9 de septiembre de 1751 figura su nombre en la nómina de religiosos en la que se consigna que contaba con treinta y dos años de edad y diez y siete en la Orden (Barriga, 1944: 241). Sus cualidades literarias fueron reconocidas por su tiempo. Este hecho se advierte especialmente en la opinión que, años después de su fallecimiento, ofreció Ignacio de Castro cuando al referirse a sus habilidades señala lo siguiente: "Bastábale oír un asunto, por elevado que fuese, para encaminarse sin desvío a todo el centro" (Aparicio 2001:259). Esta mención, sobre la capacidad de comprensión de lo medular de asuntos complejos, me interesa particularmente para situar la postura de Castillo en el contexto de su época y respecto a la obra que se tratará aquí.

Entre los textos vinculados a la conquista de América y, específicamente a la del Perú, Sabine Fritz, de la Universidad alemana de Giessen, incluyó en su artículo "La justificación de la muerte del inca Atahualpa en el teatro español de los siglos XVIII y XIX” (Fritz 2009: 229-252), la obra del criollo fray Francisco del Castillo y Tamayo OM, La conquista del Perú (1748). La autora solamente identifica cuatro obras con esta temática en España y América pues, aunque se menciona a doce en diversas fuentes, no le fue posible localizarlas. Aparte de dos en el siglo XVII en España, una de Tirso de Molina y otra de Luis Vélez de Guevara, la de Castillo es la más antigua de ellas que puede encontrarse. Lo especial de la obra del fraile mercedario es que fue escrita en Lima a mediados del siglo XVIII a propósito de la festividad por la coronación de Fernando VI, y con la singularidad de que fue encargada por el gremio de los

1 Para su nacimiento: Guillermo Lohmann Villena (Madrid 1945:413), quien encontró la partida de bautismo en la parroquia de San Marcelo (Libro 5o de Bautismo de Españoles 1701-1720, f.115 v); y La Gaceta de Lima del 27 de enero de 1771 para su muerte: Aparicio 2001:458. 
naturales, "manifestando en ella su cordial, reverente obsequio" (Debarbieri 1996:219)².

La fuente reconocida para los datos que la obra aporta fue los Comentarios Reales del Inca Garcilaso de la Vega, que por entonces era base de las reivindicaciones de la nobleza indígena andina. Esta pieza, incluida en la obra que Rubén Vargas Ugarte le dedicó a Castillo en el tomo II de sus Clásicos Peruanos (Lima, Studium 1948), fue estudiada posteriormente por Concepción Reverte Bernal quien en 1983 publicó "Notas para un estudio de la 'Mise en scene' de una comedia histórica hispanoamericana: La Conquista del Perú, de Fray Francisco del Castillo (Lima 1716-1770)" (Reverte 1983:115-128). Para el análisis que ofreceré he consultado la transcripción de César A. Debarbieri incluida en la Obra Completa de Fray Francisco del Castillo O.M. "El ciego de la Merced" 1716-1770.

El objetivo de este somero estudio es conocer la posición de la comunidad indígena con caudal suficiente para encargar una obra para una fecha significativa, como fue la coronación del nuevo rey Fernando VI, y encontrar la posible opinión sobre el hecho representado tanto en ella, como cliente aceptante del encargo, como en el escritor, partícipe de una comunidad religiosa con fuerte arraigo criollo. La motivación de este estudio también es que, en Los júbilos de Lima (1755), de Francisco Ruiz Cano y Galeano, los naturales tuvieron una presencia relevante en las festividades por la inauguración de una sección de la restauración de la catedral limeña y Fray Francisco del Castillo la describe con un conocimiento amplio de su cultura, aunque sin considerarla próxima pues frecuentemente añade la frase "del uso de ellos", así como procura distanciarse del gusto que conducía el vestuario, las danzas y la música que la comunidad nativa presentó en la fiesta.

La obra de Castillo está estructurada en jornadas, y estas en cuadros que permiten al espectador ideal conocer distintos aspectos de la historia que se pretende representar, y que se solucionan con la simple entrada o salida de escena de los personajes involucrados. No se alude a una escenografía específica $\mathrm{y}$, de acuerdo a las acotaciones, algunas de las acciones de corte masivo se escuchan fuera de la vista del espectador. La trama central no es específicamente la conquista, sino una historia de amores que se conduce entre la equivocación y el engaño y que culmina al final de la obra de manera felizmente resuelta. Sin embargo, este juego de apariencias y desengaños, en algún caso de aceptación de lo negado por inevitable y por no haber solución distinta, bien puede extenderse a la relación social que conducía a los grupos involucrados a mediados del siglo XVIII en el virreinato, y especialmente en su capital. Un

2 En adelante para lo referido a La Conquista, me limitaré a citar el número de página de la versión de César Debarbieri. Ver bibliografía. 
consentimiento motivado por la conveniencia antes que por la persuasión y que no evidencia lazos sólidos pero si convicciones firmes.

Aunque trata de la "conquista", la comedia no es un panegírico a los españoles, ni es precisamente la descripción de la conducta entre los hermanos rivales por la herencia imperial, ni el comportamiento de ambos respecto al invasor, algo que hubiese sido interesante para el momento en el que fue escrita, sino los argumentos que, expresados por ellos mismos, se presentan en el subtexto.

La historia de amores que cruza la pieza es un reflejo del motivo principal y no relevante por sí misma. En la loa inicial, un personaje denominado "La Nación peruana” comparte escenas con la Fama, Europa, el Regocijo, la Nobleza, el Amor, la Dicha, la Obligación y la Música. Está vestida "de india” y su aparición parece desconcertar a los otros personajes, al punto que la Música debe aclarar que es la "Nueva Castilla", unida a Europa en la celebración por amor al rey, lo que el personaje Europa niega porque al no conocerlo, mal haría en declarar amarlo. La representación del rey por intermedio del virrey zanja la cuestión, aunque no la actitud antagónica de Europa, que termina por admitir que la Nación peruana sustenta su derecho en el "ingenio, /y tanto que por él vales /mucho más precio en mi aprecio" (207), aunque insiste en denominarla "India" para distinguirla de sí misma (208). La Nobleza, que se puede identificar como peruana, acude en apoyo de la Nación Peruana recordando su condición de "noble" mediante los matrimonios previos con españoles que también lo eran. Y declara a Europa, "Yo soy contigo tan una/ que la separación niego, porque la unión de la sangre/ cuasi identidad se ha hecho" (211). Europa, finalmente, la reconoce como "Nación excelsa" (212) y continúa la celebración en armonía.

A poco de culminar la Loa, la Nación Peruana explica que en la comedia que seguirá "ha de representarse la lealtad y el rendimiento/con que la Nueva Castilla/ con las armas del afecto,/ libre quiso sujetarse/ al augusto hispano gremio" (217). Esta mención a la libre decisión de haber tomado el vasallaje ha sido interpretada por la crítica como intencionada, para minimizar la acción que llevó a los españoles al poder y por la cual declararon siempre gran orgullo. No será la única alusión que se orienta en sentido distinto a lo que parece señalar el texto.

Huayna Cápac inicia su intervención resaltando los valores con los que fue favorecido el Perú por los dioses, en magnitud territorial y riqueza (220-221). Hace entrega del reino a sus hijos y, con la convicción de lo implacable de los vaticinios, declara el beneficio que les traerá rendirse ante el invasor (254). Atahualpa y Huáscar, manteniendo su rivalidad y mutua desconfianza, aparecen a su vez como individuos apegados a su religión, respetuosos de sus ritos y, en concordancia a las disposiciones de su padre, convencidos de la verdad de 
lo que los dioses, presuntamente enojados, han predestinado para el Imperio a través de los oráculos, su caída. Su actitud es por tanto profundamente creyente, aunque en sentido distinto al del invasor. Otro tanto sucede con los súbditos, enterados del augurio, que se postran confirmando el poder de la cruz.

En una secuencia, y ante la sorpresa de Hernando Pizarro y Hernando de Soto que lo visitan, Atahualpa se muestra amable y obsequioso, e incluso instruye a los suyos acerca de la apariencia del dios Wiracocha que se personaliza en ellos (322), lo que no duda en comunicarles, "pues a mi dios Viracocha/ en vuestras personas veo" (323). Atahualpa, como si hablara para sí mismo, se dirige a los "Varones claros y excelsos,/ claros por hijos del Sol,/ excelsos por ser del cielo" (326) Hernando de Soto y Hernando Pizarro. En lo que sigue se infiere que los admite en tanto forman parte de su creencia personal, los presume seres celestes descendientes del Sol, así como porque respeta la disposición paterna. Después de alabar su presencia les reprocha y denuncia por la depredación del territorio, los hurtos y las muertes, "las fatalidades y estragos" que ocasionan, y que acepta en tanto comprende y admite que eran acciones emprendidas por decisión divina (327). El Inca señala irónicamente:

Por tanto, podeis hacer/

lo que fuere gusto vuestro/

de nosotros, pues nosotros/

libre ofrenda nos hacemos; /

que harta gloria será nuestra/

morir en manos de aquellos/

que, aunque inhumanos nos maten,/

por divinos los tenemos /

$y$ veneramos, juzgando /

que son de dios mensajeros./

Que él sin duda os mandaría/

los estragos que habéis hecho,/

pues como sin culpa nuestra /

contra nosotros se hicieron, /

infiero ser estas penas/

por delitos contra el cielo,/

(...) que si del dios Viracocha/

lo que hicisteis fue precepto,/

con él estamos conformes,/ 


\author{
aunque ejecutéis lo mismo/ \\ con nosotros; solo os pido / \\ y con súplicas os ruego/ \\ que con piedad a los míos/ \\ los miréis, pues es muy cierto/ \\ que mi muerte será vida / \\ como queden vivos ellos (328-329).
}

Atahualpa ofrenda el imperio en condición de martirio y utiliza el término "inhumano", que correspondería a su experiencia referida a la entrada hispana, pero inmediatamente lo vincula a lo "divino", restándole fuerza a la denuncia. Luego, atribuye la responsabilidad de los actos que venían perpetrando los españoles en el territorio con una posible orden de Viracocha, por lo que no serían directamente responsables, sino la mano del castigo divino. Una doble interpretación permite este discurso. Una, por la que el Inca exime a los españoles de responsabilidad por las tropelías pasadas, presentes y futuras, y otra, por la que se libera a sí mismo por la acción de entrega que está próximo a realizar traicionando su condición. En ambos casos la ironía es manifiesta tanto en la lectura como en su posibilidad oral. El texto autoriza esta interpretación porque evidencia que no hay entendimiento entre las partes que intervienen en este encuentro, se comprende mal el gesto y se profundiza la confusión por la inadecuada traducción de la lengua. Esto desvirtúa el que Atahualpa hubiese aceptado la superioridad de la cultura del extranjero (Fritz 1009:239), la acepta por disposición divina, no por convicción.

Queda claro que cada grupo en el encuentro desarrolla su discurso para sí y mantiene lo previsto sin variación ni conciliación. Atahualpa se ofrece y entrega su gobierno con prodigalidad sospechosa, y en el contexto de la época, no creo que este punto haya pasado desapercibido a los espectadores. Otro tanto sucede con los españoles que malician de su gesto amable, y desconocen el razonamiento que lo acompaña. La misma condición se presenta en la entrevista del Inca con Vicente de Valverde pero, en esta oportunidad, Atahualpa señala expresamente la dificultad de la inadecuada traducción, así como es consciente de la manipulación del intérprete (336). Antes de su captura el Inca se rinde, conscientemente, respondiendo al vaticinio. Parece abandonarse, no por certidumbre sino por su profunda creencia en su propia fe (336-337). Así, exhortará a sus súbditos a seguirlo, aunque sospecha que hay "misterios escondidos" en las leyes españolas, y anota una advertencia a los suyos: "Ahora conoceréis / si la ley de Jesucristo/ es verdadera o falsa" (338), en el sentido de que así como se desintegró la religión propia, había que someter a juicio la ajena, lo que es 
inmediatamente refutado por las voces fuera de escena (338). En respuesta, Atahualpa se bautiza. Rumiñahui es entre los presentes el que, rebelde, no acepta hacerlo y decide retirarse a Quito. Los hechos de Cajamarca que culminaron en la posterior muerte de Atahualpa se deducen del texto, pero no se materializan en escena.

Un detalle significativo es que el único personaje que parece mantenerse alerta, consciente del error en el que están incurriendo el Inca y el pueblo que lo sigue en su conducta ante el invasor, es el runa Llupanguillo, un hombre común, sirviente de Rumiñahui que a su vez lo es de Huascar, cuyo único recurso para mantenerse vivo es convertirse en bufón de alguno de los ambiciosos hermanos. Llupanguillo advierte los despropósitos que se están cometiendo y es como la consciencia colectiva que puede proyectarse ante el peligro, pero que no tiene la autoridad para hacerse escuchar. Bien se le evidencia a él mismo cuando, por bromear, se hace pasar por el Inca quien al descubrirlo, y arrojarlo al suelo con violencia, lo califica de "Bárbaro sin reflexión ... sujeto bajo" (330), y lo condena a muerte. No se llega a cumplir la sentencia pues es él quien cierra la comedia señalando "que en el teatro se ha visto/ la conquista del Perú;/ muchos yerros ha tenido/ mas no se espanten que el poeta/ dicen que a tiento la ha escrito,/ y así, porque de limosna/ se le pueda dar un vítor,/pues es discreto el senado,/no se dé por entendido" (340).

La alusión a la ceguera o miopía del autor releva de una interpretación sesgada, pues se extiende a la focalización de su escrito. Castillo mantiene la distancia en las acotaciones y no puede suponerse que está a favor de una u otra postura, pues si bien los españoles no comprenden la intención de Atahualpa de entregarles el imperio, sí se muestran gratamente asombrados por su calidad de soberano y la riqueza de sus territorios. Castillo cuando se refiere a la nación indígena cuida de acotar: "entre los indios se tenía" o "la que ellos tejían" (318), una actitud de diferenciación que también se encuentra en Francisco Antonio Ruiz Cano.

La obra de teatro fue aceptada por los clientes que la encargaron, el gremio de los naturales, y no pareció causar malestar en su representación, que es una posibilidad sostenida por Reverte debido a que en el texto se indica "comedia famosa", condición que solamente se reconocía a aquellas que se llevaban a escena. También es significativa la ocasión en la que se ofreció y la fecha de la misma. No considero, como señala Fritz, que la obra se inscriba en el contexto de minimizar las acciones de conquista, y denunciar la marginación criolla de la administración española. Es cierto que a los conquistadores se les muestra ambiciosos e inescrupulosos, pero es distinta la posición de los clientes que encargaron la pieza. La loa orienta la lectura. Lo que se revindica es la nobleza de los naturales, su condición civilizada, pues en la obra participan de 
los mismos principios que conducían la acción española. El Inca se comporta como un soberano por derecho y distinción, así lo reconocen los españoles y por ello mismo dudan de su rápida aceptación a dejar su dominio en manos de extranjeros. Incluso, también entre sus súbditos se presenta la rivalidad amorosa basada en el galanteo y el honor, en nada diversa a la de los seres considerados como civilizados. Posiblemente La conquista del Perú no sea un manifiesto nacionalista explícito, porque involucró solamente a un sector de la nación peruana, pero es un síntoma de la percepción que se tenía del Perú como ente comprometido con su condición culturalmente autónoma. Es una obra sutilmente reivindicativa, en la que se destaca que los principios que regían el gobierno anterior a la incursión española, no tuvieron una orientación intrínsecamente diferente a la que se pretendía haber implantado en su territorio como novedosa (Barriga Tello 2003) ${ }^{3}$.

Igualmente, en el discurso de Atahualpa a los españoles, no puede obviarse los versos “...solo os pido /y con súplicas os ruego/ que con piedad a los míos/ los miréis, pues es muy cierto/ que mi muerte será vida / como queden vivos ellos" (329). Atahualpa previene la supervivencia de su estirpe y cultura en sus descendientes, precisamente quienes estaban rindiendo homenaje al nuevo rey con esa representación, una poca sutil confirmación de la intención reivindicativa que en términos generales tiene la pieza. Es significativo que esta obra tuviera libre curso en la celebración real, fuera celebrada y que haya permanecido.

También lo es, y solamente para confirmar la posible orientación del autor, uno de sus Romances, el № 5, titulado "Conversación de un Negro, mayordomo de chacra, con un Indio Alcalde de Camaroneros, en la calle de los Borricos". En este, un indio decide emigrar hacia el Ande porque "después de cincuenta años,/ entre españoles viviendo,/ le han pagado estos tan mal,/ que tiene a su nombre miedo" $(952)^{4}$, pues no había logrado establecerse a pesar de sus múltiples intentos. En su recorrido sobre una débil mula, Nicolás Quispe, Alcalde de camaroneros, se encuentra con el negro Miguel Torres que lo hacía sobre un brioso y ricamente enjaezado caballo. Le cuenta sus decepciones y sus esfuerzos, "Bien sabe U. que he corrido/ en este infeliz tiempo/ cuantos humildes oficios/ dio la suerte a nuestro gremio./ Yo fui Pastor, a pesar / de mi regio nacimiento,/ mas también lo fue David/ y siéndolo, empuñó el cetro" (953). Nicolás lo había intentado todo y, a pesar de su honradez y lealtad, o tal vez

3 En este artículo, el análisis de testimonios del siglo XVI evidencian la profunda convicción autónoma del pueblo peruano, y su certeza de ser parte de un imperio por derecho y equivalente al europeo.

4 Debarbieri declara que se ha transcrito la versión que publicó Rubén Vargas Ugarte SJ en el tomo II de Clásicos Peruanos, que dedicó a Castillo (Lima, Studium, 1948) limitándose a subsanar errores de impresión. Se citará de la versión de Debarbieri. 
por ello mismo como deja entrever, había encontrado desconfianza y rechazo cualquiera fuera el oficio que emprendiera entre los posibles para su "gremio", un elemento que signa una primera alusión a la discriminación por el trabajo. Significativamente, Nicolás se reconoce de origen noble, condición que podría haber evitado sus intentos, pero alude en comparación a David, reconociendo que el oficio no hace al hombre, no lo desmerece en su honor. Sus desgracias, incluso, lo habían llevado a pasar un tiempo en la cárcel de Corte, falsamente acusado. En un momento se queja del sistema, que lo aparta como a extranjero sin reconocer su derecho de origen ni sus valores:

Y siendo, gracias a Dios, /

yo natural de estos Reynos/

me hubieran hecho alemán/

por reputarme extranjero./

Porque veo que a los Indios,/

No sé con qué fundamento,/

Les levantan testimonios/

de mayor gravedad que estos./

Y ellos solamente son/

Los idólatras perversos/

Con mayor obstinación/

Que las del ingrato hebrero./

$\mathrm{Y}$ las tres partes y media/

De nuestro vasto universo,/

Por varios modos incurren/

En tan execrable yerro./

Sólo a ellos se les imputa/

El delito de ser ebrios,/

Vicio que se le atribuye/

Al mundo, según su tiempo/

(...)

a ellos solos se atribuye/

lo falaz y lo embustero/

cuando Dios ha declarado/

en todo hombre este defecto (957-958) 
Quispe no continúa porque, displicentemente, lo interrumpe Torres que, al tiempo de darle la razón en todo lo que ha expresado, "todo es infalible y cierto", le reprocha la conducta de su nación.

\author{
Bien sé que la voz primera/ \\ Que pronuncia el niño tierno/ \\ Es: perro indio, perro cholo/ \\ Y otros elogios como estos/, \\ Pero conozco también/ \\ Que siempre las voces fueron/ \\ Los signos más evidentes/ \\ De lo que abunda en el pecho (959).
}

Torres señala que la actitud de los blancos contra el indio era el querer evitar una posible vinculación con él por la sangre, ante el peligro de ser identificados como mestizos, circunstancia que era claramente advertida por los naturales. "Este vicio es necesario/en la mayor parte, puesto/ que de la conquista debe/ reputarse como efecto,/ porque los conquistadores/ tienen por baldón horrendo/ ser conquistados, al modo / que el vencedor ser trofeo (....) pero en los que ha sucedido /champurreando con mezcla, a estos /es una acción vergonzosa/ y llena de vilipendio. (...) creyendo que de esta suerte/ se acreditan de no serlo/y que están de imputación /de indios viles a cubierto; y así he oído a muchos indios /que estos reproches oyendo,/ vuelven caquinos de risa/ en pago del sentimiento/ y dicen en tono bajo:/ lo que eres me dices, necio"(959). Nicolás Quispe no se había percatado de esta situación, por lo que los versos de su queja no estuvieron orientados a suscitar compasión, sino a advertir de un hecho concreto.

Miguel Torres también le revela que la situación distinta de la relación de los españoles con su raza era que, al contrario de los indios que se mostraban tristes, melancólicos y serios, ellos no ofrecían resistencia, se adecuaban a todo servicio, los complacían, encubrían sus debilidades y, de este modo, lograban beneficios en otras circunstancias impensables (961). Torres tiene una postura que aunque cínica y desvergonzada, pues se basa en el engaño y el disimulo tanto como aprovecha las situaciones sin el menor escrúpulo, no puede censurársele pues la esgrime como efectivo medio de supervivencia ante una circunstancia que necesitaba de respuestas hábiles, "con que es así, buen Nicolás, /que es cornudo argumento/y han de mudar de sistema/ o reventar, que no hay remedio" (961) concluyó Miguel Torres, y se marchó. Quispe, al contrario, actuaba correctamente, seguía las normas y era honrado, por lo que generaba 
desconfianza y se convertía en un peligro, no solamente por lo que significaba el vínculo de sangre, sino porque compartía valores coincidentes con los de un sector social que no estaba dispuesto a tratarlo en nivel de igualdad y convertirlo en par. Es la condición de lealtad que presenta Llupanguillo y la nobleza que muestra Atahualpa que, en contra de su natural condición de autoridad y poder, se decide por el bien del colectivo en desmedro propio, aunque tiene la aspiración de permanecer en la supervivencia de los suyos.

El gremio de los naturales confió bien en Francisco del Castillo. El lego mercedario conocía de la intolerancia y de los conflictos que debía enfrentar una persona a quien, relegándosele injustamente a una posición de minusvalía, se le pretendió negar los derechos de sangre, de posición y de decidir de acuerdo a sus convicciones. Él enfrentó una situación dramática que, considerando la certeza que tuvo en su capacidad y siendo reconocido como un personaje excepcional por sus contemporáneos, debió coincidir con la experiencia del Gremio de Naturales. La Conquista del Perú es una pieza de convicción y, junto a la opción abierta que deja el romance № 5 , convida a reflexionar, a tomar consciencia de la propia condición y decidir. En un momento significativo para la historia posterior del Perú, La Conquista del Perú fue escenificada y celebrada. El Gremio de los Naturales y Francisco del Castillo fueron escuchados.

\section{Referencias bibliográficas}

APARICIO, Severo O.M., (2001) La Orden de la Merced en el Perú. Estudios Históricos. Tomo II. Cuzco: Provincia Mercedaria del Perú.

BARRIGA, Víctor M. OM. (1944) El Templo de la Merced de Lima. Documentos para la Historia del Arte. Arequipa: Establecimientos Gráficos la Colmena, S.A.

BARRIGA TELLO, Martha (2003) "El arte en el origen de un desencuentro: Dos imperios en el Perú del siglo XVI" en Patio de Letras, Año I, Vol. I, Lima; pp. 71-79.

DEBARBIERI, César A. (1996) "Introducción" en Obra Completa de Fray Francisco del Castillo Andraca y Tamayo O.M. "El ciego de la Merced" 1716-1770. Lima: Edición de César Debarbieri.

FRITZ, Sabine (2009) "La justificación de la muerte del inca Atahualpa en el teatro español de los siglos XVIII y XIX” en Floeck, Wilfried y Sabine Fritz (editores) $L a$ representación de la Conquista en el teatro español de la Ilustración hasta finales del franquismo. Hildesheim. Zurich. New York, Georg Olms Verlag; pp. 229-252.

LOHMANN Villena, Guillermo (1945) El Arte Dramático en Lima Durante el Virreinato. Madrid: Escuela de Estudios Hispanoamericanos de la Universidad de Sevilla.

REVERTE BERNAL, Concepción (1983) "Notas para un estudio de la 'Mise en scene' de una comedia histórica hispanoamericana: La Conquista del Perú de Fray Francisco del Castillo (Lima 1716-1770)" en Anales de literatura hispanoamericana, 12; pp. 115-128. 